\title{
Electronic Properties and Charge Density Transfer of $\mathrm{MoTe}_{2}$
}

\author{
Fareed M. Mohammed, Awatif S. Jassim, Shahad A. Shaaban, Fatimah I. Rashid \\ Department of physics/College of Science/U.O. Tikrit-Iraq.
}

Correspondence Author: Fareed M. Mohammed, Department of physics/College of Science/U.O. Tikrit-Iraq.

E-mail: dr_fr_2006@yahoo.com

Received date: 15 April 2018, Accepted date: 15 June 2018, Online date: 5 July 2018

Copyright: () 2018 Fareed M. Mohammed, et al. This is an open-access article distributed under the terms of the Creative Commons Attribution License, which permits unrestricted use, distribution, and reproduction in any medium, provided the original author and source are credited.

\begin{abstract}
The theoretical study to calculate Compton profiles for molybdenum dichalcogenide (MoTe2) are present in this paper by using a number of models (RFA, FE and superposition) models, the comparison between the calculated and available experimental data shows relatively an accepted agreement. To estimate the charge transfer of compound formation (Mo-x) $(\mathrm{Te}+\mathrm{x} / 2) 2$ the ionic model is adopted for number of arrangements, these supports transfere of 1.4 electrons from $5 \mathrm{p}$ shell of each (Te2) atom to $4 \mathrm{~d}$ shell of (Mo).
\end{abstract}

Key word: Superposition (S.P.) model, $\mathrm{MoTe}_{2}$, Compton profile (CP), Hartree Fock HF, charge transfor, Renormalized Free Atom (RFA), Free Electron (FE), Free Atom (FA)

\section{INTRODUCTION}

When $\mathrm{x}$ or Y-rays inelastically scattering from an electron the resulting beam is Doppler broadening because of the target electrons motion. The electron momentum distributions in a solid have been investigated by measuring the energy spectrum of Compton scattering at a fixed scattering angle. The energy spectrum in Compton profile momentum scale is directly related with the electrons momentum distribution. The Compton scattered radiation spectral analysis reveals the line form according to impulse approximation (IA) which suppose that the reaction time implicated in the Compton scattering is very small that the initial electron and final electron have the same fixed potential energy. In the impulse approximation " the Compton profile $\mathrm{J}(\mathrm{q})$ is the one dimensional projection of the momentum distribution $\mathrm{n}(\mathrm{p})$ on the scattering vector, along the $\mathrm{z}$-axis of the Cartesian system" i.e.

$J(q)=\iint n(p) d p_{x} d p_{y}$

Hence, it is used as a strong tool for the realization of electronic structure of material, in the condition that the impulse approximation remains correct (Williams, B.G., 1977; Cooper, M.J., 1985).

The technique is in particular sensitive to the conduct of the slowly moving external electrons implicated in bonding in condensed substance and serves as a dependable test of the accuracy of the computed wave functions. This basic information is salutary in the study of all the physical properties of the system.

Molybdenum telluride is a compound of the molybdenum and the tellurium, the mass percentage of molybdenum $27.32 \%$ and tellurium $72.68 \%$.

In molybdenum dichalcogenides $\mathrm{MoTe}_{2}$ the metals atoms in the sequential layers are displaced such that the produce structure form the layers $2 \mathrm{H}$-polytype , these layers transition metal dichalcogenide compounds (LTMDC). The $\mathrm{MoTe}_{2}$ is applied as electrodes in photo of electrochemical cell.

McGovern et al. (1979) have undertaken the photoelectron spectroscopy on MoTe 2 . Whilst Hind Lee (1980) reign applied the Korringa Kohn Rostoker method to calculate the energy band of the compound. The photocurrent spectroscopy of the individual crystals of semiconductor group transition metal dichalcogenide has been reported by Kam and Parkinson (1982). Dawson and Bullett (1987) have complete the ab initio narrow binding calculation for the electronic structure of $\mathrm{MoTe}_{2}$. Böker et al. (2001) have offered the valence band structure of MoTe 2 employing Angular-Resolved-Photoelectron-Spectroscopy (ARPES). In this paper, we report the ever theoretical Compton profiles of MoTe $\mathrm{T}_{2}$. For the calculation of electronic properties and theoretical Compton profiles we have used several models for this purpose.

2. Theory:

2.1.Renormalized Free Atom (RFA) model:

The Berggren approach to calculate Compton profile of polycrystalline elements were applied, Since the scheme of calculation of Compton profile of valance electrons is accredited (Berggren, K.F., 1972; Ahuja, B.L., 1987). The wave function for the free atom for the elements were taken from Hartree Fock tables (Clementi, E. and C. Roetti, 1974), it has been amputate at the wigner - seitz radius and then renormalized to one unity to preserve neutrality of the charge. The wave function $\mathrm{R}_{\mathrm{nl}}(\mathrm{r})$ are given in the following formula:

$\mathrm{R}_{\mathrm{nl}}(\mathrm{r})= \begin{cases}\mathrm{N}_{\mathrm{nl}} \mathrm{R}_{\mathrm{nl}}^{\text {atomic }(\mathrm{r})} & \mathrm{r} \leq \mathrm{R}_{0} \\ 0 & \mathrm{r}>\mathrm{R}_{0}\end{cases}$

Then the new wave function will be used in further computation, in this model the solid is constructed of individual atom approximately in the same shape in which they really enter the solid before bounding together.

As for the successes of this model beside Compton work (Timms, D.N. and M.J. Cooper, 1993) have view that this simple model gives correct estimates of band structure properties and also an explanation for cohesion in the transition metal series.

Compton profile of 5 s electrons is given by (Berggren, K.F., 1973): 
$\mathrm{J}_{5 \mathrm{~s}}\left(\mathrm{P}_{\mathrm{Z}}\right)=4 \pi \sum_{\mathrm{n}=0}^{\infty}\left|\Psi_{0}^{\mathrm{c}}\left(\mathrm{k}_{\mathrm{n}}\right)\right|^{2} \mathrm{G}_{\mathrm{n}}\left(\mathrm{P}_{\mathrm{Z}}\right)$

Were $\Psi_{0}^{c}\left(k_{n}\right)$ is the fourier transformation of the wave function, $G_{n}\left(P_{Z}\right)$ is an auxiliary function include reciprocal lattice vector ( $\left.k_{n}\right)$ in reciprocal space point number in the $\mathrm{n}^{\text {th }}$ shell, Fermi momentum $\left(\mathrm{P}_{\mathrm{F}}\right)$, etc. to implication the crystalline effect.

The $\mathrm{G}_{\mathrm{n}}\left(\mathrm{p}_{\mathrm{n}}\right)$ given as

$\mathrm{G}_{\mathrm{n}}\left(\mathrm{P}_{\mathrm{Z}}\right)=\frac{N \mathrm{nn}}{4 \mathrm{k}_{\mathrm{n}}}\left\{\left(\mathrm{P}_{\mathrm{F}}^{2}-\mathrm{K}_{\mathrm{n}}^{2}\right)\left(\mathrm{K}_{\mathrm{n}}+\mathrm{P}_{\mathrm{F}}-\mathrm{P}_{\mathrm{Z}}\right)-\frac{1}{3}\left[\left(\mathrm{~K}_{\mathrm{n}}+\mathrm{P}_{\mathrm{F}}\right)^{3}-\mathrm{P}_{\mathrm{Z}}^{3}\right]+\mathrm{K}_{\mathrm{n}}\left[\left(\mathrm{K}_{\mathrm{n}}+\mathrm{P}_{\mathrm{F}}\right)^{2}-\mathrm{P}_{\mathrm{Z}}^{2}\right]\right\}$

For more details see Berggren (1972).

Electron:

The procedure for calculating Compton profile is already published and here we have re-write equation for the purpose of completeness the momentum transform for a Bloch function of the cubic structures is written as:

$\Psi_{0}^{\mathrm{c}}\left(\overrightarrow{\mathrm{k}}_{\mathrm{n}}\right)=(2 / \pi)^{1 / 2} \mathrm{k}_{\mathrm{n}}^{-1} \int_{0}^{\mathrm{r}_{0}} \mathrm{dr} \mathrm{r} \sin \left(\mathrm{k}_{\mathrm{n}} \mathrm{r}\right)\left[\emptyset_{0}^{\mathrm{c}}(\mathrm{r})-\emptyset_{0}^{\mathrm{c}}\left(\mathrm{r}_{0}\right)\right]$

Then the Compton profile was calculated using equ.(3) to (5) for several cases selecting various (d-s) configuration.

The Compton profile values of "d" electrons and other core electrons were taken from Bigges (1975).

\subsection{Free Electron (FE) model:}

In case of an electronic properties equ. (1) reduces to the following form:

$\mathrm{J}_{5 \mathrm{~S}}\left(\mathrm{P}_{\mathrm{Z}}\right)=2 \pi \int_{\mathrm{P}_{\mathrm{Z}}}^{\infty} \mathrm{dp} \mathrm{n}(\overrightarrow{\mathrm{p}}) \mathrm{p}$

If we take the valence electron in the metal as a non reactive electron gas then the momentum distribution is:

$\mathrm{n}(\overrightarrow{\mathrm{p}})=\frac{\mathrm{n}}{\frac{4}{3} \pi \mathrm{p}_{\mathrm{F}}^{3}}=$ constant

$\mathrm{n}$ is number of free electron per position, the $\mathrm{P}_{\mathrm{F}}$ is the Fermi momentum.

Substitution of $n(p)$ from equ.(7) to equ.(6) give:

$\mathrm{J}_{5 \mathrm{~S}}\left(\mathrm{P}_{\mathrm{Z}}\right)=\frac{3 \mathrm{n}}{4 \pi \mathrm{P}_{\mathrm{F}}^{3}}\left(\mathrm{p}_{\mathrm{F}}^{2}-\mathrm{p}_{\mathrm{Z}}^{2}\right) \quad$ for $\mathrm{P}_{\mathrm{Z}} \leq \mathrm{P}_{\mathrm{F}}$

2.3. Superposition (S.P) model:

The formula of the Compton profile of given compound $J^{\text {sup. }}\left(\mathrm{p}_{z}\right)$ of $\left(\mathrm{MoTe}_{2}\right)$ is as follows:

$\mathrm{J}^{\mathrm{SUP}} \cdot\left(\mathrm{P}_{\mathrm{Z}}\right)=\mathrm{J}^{\mathrm{Mo}}\left(\mathrm{P}_{\mathrm{Z}}\right)+\mathrm{J}^{\mathrm{Te}}\left(\mathrm{P}_{\mathrm{Z}}\right)$

$\mathrm{J}^{\mathrm{Mo}}\left(\mathrm{P}_{\mathrm{Z}}\right)$ and $\mathrm{J}^{\mathrm{Te}}\left(\mathrm{P}_{\mathrm{Z}}\right)$ are the calculated Compton profiles of Mo and Te metals respectively. The $\mathrm{J}\left(\mathrm{P}_{\mathrm{Z}}\right)$ values of constituent metals Mo and Te were taken from the present work. For the sake of comparison the obtained theoretical values for Mo and Te were convoluted with the Residual-Instrument-Function (RIF) for the surpose of appropriate comparison with the experiment because no deconvolution execution removes the instrumental expanding totally due to statistical noise always present in the experiment (Paakkari, T. and S. Manninen, 1974).

\section{RESULTS AND DISCUSSION}

\section{For Mo metal:}

Table (1) show three theoretical profiles for (Free atom, Free electron and RFA). All values given in this table are normalized to an area under curve of free atom (17.00624) being the number of electron from 0 to 7 a.u. expect $1 \mathrm{~s}^{2}$ electrons because it's not contributed in the scattering process also the recrudesces reason to the incident energy of $\mathrm{Am}^{241}$ is smaller than the binding energy of $1 \mathrm{~s}^{2}$ electrons in $\mathrm{K}$ shell. In the same table the $1^{\text {st }}$ column included momentum zone, the $2^{\text {nd }}$ column represents Free atom values, the $3^{\text {rd }}$ column shows Free electron results, the $4^{\text {th }}$ column included the best arrangement of RFA values and the final column are the experimental data (Mohammad, F.M., 1989). All the theoretical results in the high momentum zone ( $\mathrm{p}_{\mathrm{z}}>1.8 \mathrm{a} . \mathrm{u}$.) are nearly equal because in the zone core electron contribute in the calculation. The free atom model shows disagreement with the experimental at the low momentum zone electron values are higher than the experimental but the RFA values are close to the experimental. Fig(1) shows comparison between the theoretical Compton profile and experimental data. The RFA results are lower than free electron at $\left(\mathrm{p}_{z}<0.5 \mathrm{a}\right.$.u. $)$ but the trend is reversed at $\left(\mathrm{p}_{z} \geq 0.8\right.$ a.u. $)$ and the RFA results are higher than the free electron values. The free atom results are higher than the free electron in the low momentum but the trend reversed between $\left(0.3 \leq \mathrm{p}_{z} \leq 0.8\right)$ a.u. and the free electron results are larger than the free atom. When ( $\mathrm{p}_{z} \geq 1.6$ a.u.) all theoretical models results become nearly similar. Fig (2) show the different between theoretical and experimental profiles in Mo. $\left(J_{\mathrm{FA}}\left(\mathrm{p}_{\mathrm{z}}\right)-\mathrm{J}_{\text {exp. }}\left(\mathrm{p}_{\mathrm{z}}\right)\right)$ is larger than $\left(\mathrm{J}_{\mathrm{FE}}\left(\mathrm{p}_{\mathrm{z}}\right)-\mathrm{J}_{\text {exp. }}\left(\mathrm{p}_{\mathrm{z}}\right), \mathrm{J}_{\mathrm{RFA}}\left(\mathrm{p}_{\mathrm{z}}\right)-\mathrm{J}_{\text {exp. }}\left(\mathrm{p}_{\mathrm{z}}\right)\right)$ in the low momentum but $\left(\mathrm{J}_{\mathrm{FA}}\left(\mathrm{p}_{\mathrm{z}}\right)-\mathrm{J}_{\text {exp. }}\left(\mathrm{p}_{\mathrm{z}}\right), \mathrm{J}_{\mathrm{FE}}\left(\mathrm{p}_{\mathrm{z}}\right)-\mathrm{J}_{\text {exp. }}\left(\mathrm{p}_{\mathrm{z}}\right)\right.$ and $\left.\mathrm{J}_{\mathrm{RFA}}\left(\mathrm{p}_{\mathrm{z}}\right)-\mathrm{J}_{\text {exp. }}\left(\mathrm{p}_{\mathrm{z}}\right)\right)$ are nearly the same in the high momentum. To obtain the best electron configuration the summation del square $\sum_{0}^{7 \mathrm{a} . u}|\Delta \mathrm{J}|^{2}$ was performed for all case. The values found to be $(2.806863,0.1513667,0.8827975)$ for (FA, Free Electron, RFA) hence the free electron model gives the lowest difference, so the best electron configuration for Mo is $4 \mathrm{~d}^{5} 5 \mathrm{~s}^{1}$.

Superposition for $\mathrm{MoTe}_{2}$ :

The theoretical values of Compton profiles for $\mathrm{MoTe}_{2}$ are calculated by employing the best electron arrangement $\left(4 \mathrm{~d}^{5} 5 \mathrm{~s}^{1}\right)$ for Mo by using RFA, FE and FA models also we take the Compton profile values of free atom for Te from Biggs et al. (1975) to get the theoretical Compton profile of MoTe ${ }_{2}$, we used the relation.

$$
\mathrm{J}_{\text {sup. }}^{\mathrm{X}}\left(\mathrm{P}_{\mathrm{Z}}\right)=\mathrm{J}_{\text {theo. }}^{\mathrm{Mo} / \mathrm{e}-}\left(\mathrm{P}_{\mathrm{Z}}\right)+\mathrm{J}_{\text {theo. }}^{\mathrm{Te} / \mathrm{e}+}\left(\mathrm{P}_{\mathrm{Z}}\right)
$$

Where $\mathrm{x}$ varied from 0 to 2 in the step of 0.1 . All the theoretical values and experimental normalized to an area under curve (57.27953) being the number of electrons from 0 to 6 a.u. The final results of total Compton profile are presented in table $(2)$ the $1^{\text {st }}$ column included momentum zone $\left(\mathrm{p}_{\mathrm{z}}\right)$, the $2^{\text {nd }}$ column represents Free atom $\mathrm{J}\left(\mathrm{P}_{\mathrm{Z}}\right)$ values, the $3^{\text {rd }}$ column shows Free electron results, the $4^{\text {th }}$ column included the best arrangement of $\mathrm{RFA}$ values and the final column are the experimental data (Heda, N.L., 2010).

Figure (3) shows comparison between the calculated (theoretical) and measured (experimental) values (Heda, N.L., 2010). When $\mathrm{P}_{Z}<0.5 \mathrm{a}$.u. it is seen that the RFA theoretical superposition of $\mathrm{MoTe}_{2}$ results are lower than free electron and free atom values, but at ( $\mathrm{P}_{\mathrm{Z}}>0.6$, upto 2) a.u. the trend is reverse and the RFA theoretical superposition of $\mathrm{MoTe}_{2}$ results are higher than (free electron , free atom). To show the differences more clearly the differences $\Delta \mathrm{J}=\left(\mathrm{J}_{\text {Theo.- }} \mathrm{J}_{\mathrm{Exp}}\right.$. $)$ are 

55.

plotted as shown in Figure 4. to select the best theoretical models by applying the superposition model which salisfy the experimental results, the summation Del square are done i.e. $\sum_{\mathrm{p}_{\mathrm{z}}=0 \text { a.u. }}^{6 \mathrm{a} . \mathrm{J}}|\mathrm{J}|^{2}$ and it is found that the values found to be $(31.9866,1.80701,1.385189)$ for (Free Atom, Free Electron, RFA).

Charge transfer for $\mathrm{MoTe}_{2}$ :

The simple ionic model were used to check wether there are any charge transfer between the two metals constituent of MoTe $\mathrm{C}_{2}$.

Case 1 : when complete transfer of valence electrons to Tellurium $5 \mathrm{p}$ orbitals of $\mathrm{Te}_{2}$ was considered:

$\mathrm{J}\left(\mathrm{P}_{\mathrm{Z}}\right)\left[(\mathrm{Mo})^{+5}\left(\mathrm{Te}^{-2}\right)^{2.5}\right]=\mathrm{J}\left(\mathrm{P}_{\mathrm{Z}}\right)\left\{\left[2 \mathrm{~s}^{2} \ldots 4 \mathrm{~d}^{0}\right] \mathrm{Mo}+\left[1 \mathrm{~s}^{2} \ldots 5 \mathrm{p}^{8}\right] \mathrm{Te}_{2}\right\}$

The Compton profiles for various orbitals were taken from tables of Biggs et al. (1975). To obtain the contribution of Te ${ }^{-2}, 2.5$ electrons were added to $5 \mathrm{p}$ orbitals of Te increasing their contribution suitably.

Case 2: partial iconicity here we started with the experimatal_ $J\left(\mathrm{P}_{\mathrm{Z}}\right)$ profile of Mo and find out the contribution for each valeuse electron by sultracting the corres ponding core _ contribution and dividing by the number of valence electrons . this contribution a fler proper multiplication was removed from the contribution of metallic constitutions and then the contribution due to $\mathrm{Te}^{-1}$ was added as discussed in case 1 that is :

$\mathrm{J}\left(\mathrm{P}_{\mathrm{Z}}\right) \exp .\left\{2 \mathrm{~s}^{2} \ldots . .4 \mathrm{~d}^{5}\right\}-\mathrm{J}\left(\mathrm{P}_{\mathrm{Z}}\right)$ core $\left\{2 \mathrm{~s}^{2} \ldots . .4 \mathrm{p}^{6}\right\}=\mathrm{J}\left(\mathrm{P}_{\mathrm{Z}}\right)$ valence

$\mathrm{J}\left(\mathrm{P}_{\mathrm{Z}}\right)$ for one valence electron $=\mathrm{J}\left(\mathrm{P}_{\mathrm{Z}}\right)$ valence $/ 5$

The results shows that in both cases the theoretical $\mathrm{J}\left(\mathrm{P}_{\mathrm{Z}}\right)$ are far away from experimental values, hence we try a partial fractional charge traws from Te $e_{2}$ to Mo in $\mathrm{MoTe}_{2}$ compound, the results support the transfer of 1.4 electrons from $5 \mathrm{p}$ orbital of $\mathrm{Te}_{2}$ to $4 \mathrm{~d}$ orbital of Mo.

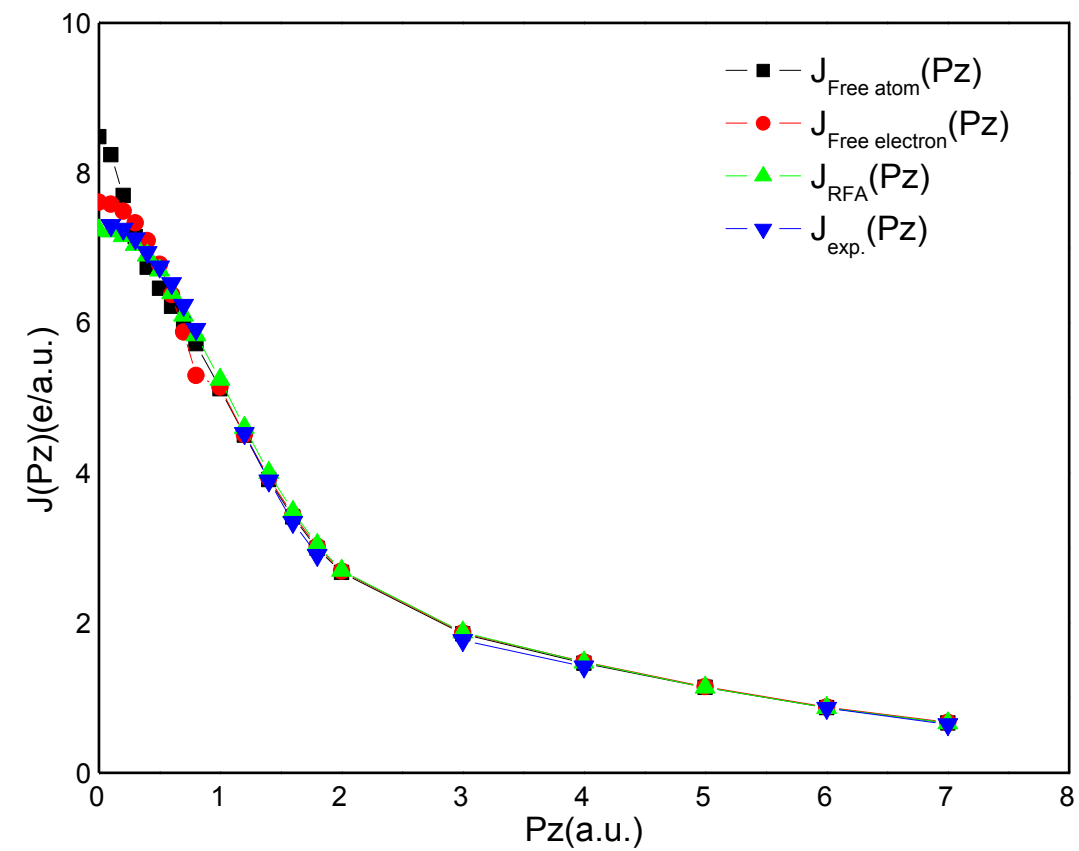

Fig. 1: Comparison of various theoretical Compton profiles values with the experimental (Mohammad, F.M., 1989) for Mo.

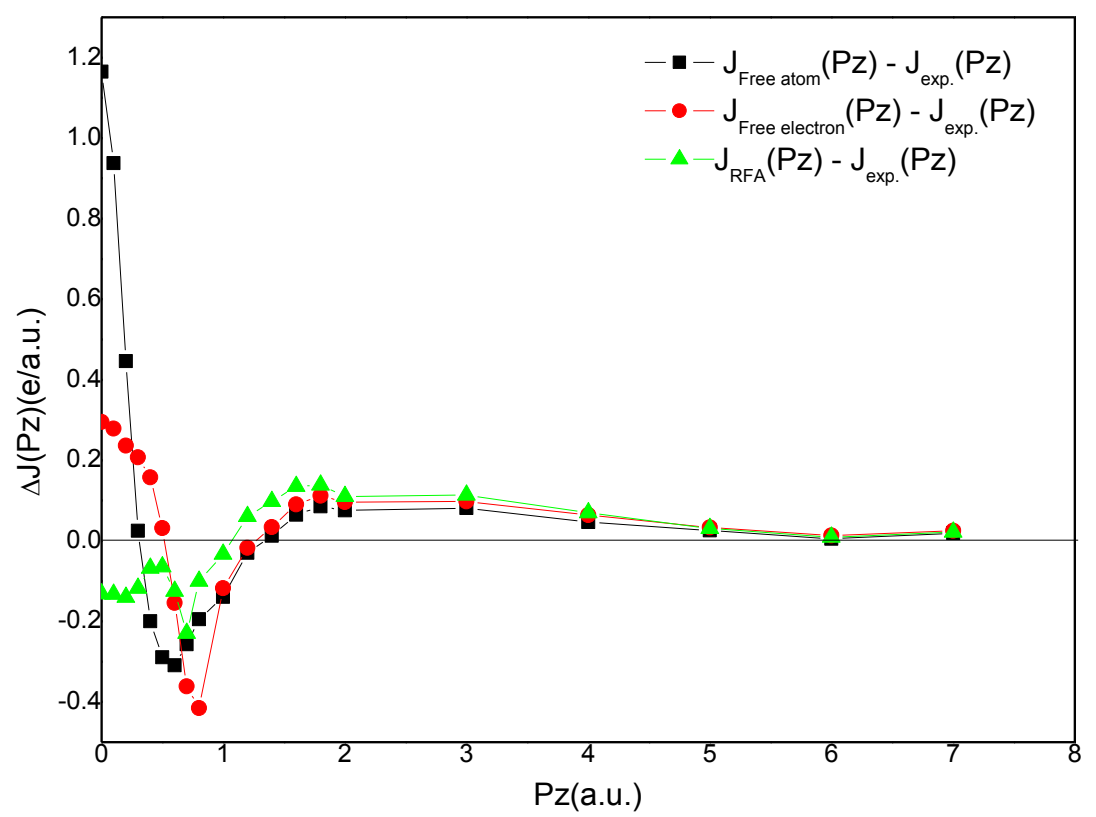

Fig. 2: Difference between the theoretical Compton profiles and the experimental (Mohammad, F.M., 1989) of Mo. 
Citation: Fareed M. Mohammed et al., Electronic Properties and Charge Density Transfer of $\mathrm{MoTe}_{2}$. Australian Journal of Basic and Applied Sciences, 12(7): 5055.

Table 1: Gives all the theoretical Compton profiles $\mathrm{J}\left(\mathrm{P}_{\mathrm{Z}}\right)$ values for (Mo) with the experimental values (Mohammad, F.M., 1989).

\begin{tabular}{|c|c|c|c|c|}
\hline \multirow[b]{2}{*}{$\mathrm{P}_{\mathrm{Z}}$ (a.u.) } & \multicolumn{3}{|l|}{$\mathrm{J}\left(\mathrm{P}_{\mathrm{Z}}\right)$} & \multirow[b]{2}{*}{ Exp.[15] } \\
\hline & $\begin{array}{l}\text { Free atom } \\
\left(4 d^{5} 5 s^{1}\right)\end{array}$ & $\begin{array}{l}\text { Free electron } \\
\left(4 d^{5} 5 s^{1}\right)\end{array}$ & $\begin{array}{l}\text { Core+RFA } \\
\left(4 d^{5} 5 s^{1}\right)\end{array}$ & \\
\hline 0 & 8.48 & 7.610 & 7.237 & $7.315 \pm 0.046$ \\
\hline 0.1 & 8.24 & 7.581 & 7.223 & 7.302 \\
\hline 0.2 & 7.7 & 7.491 & 7.162 & 7.254 \\
\hline 0.3 & 7.15 & 7.332 & 7.046 & 7.125 \\
\hline 0.4 & 6.74 & 7.097 & 6.901 & 6.94 \\
\hline 0.5 & 6.46 & 6.780 & 6.701 & 6.749 \\
\hline 0.6 & 6.22 & 6.375 & 6.398 & 6.529 \\
\hline 0.7 & 5.98 & 5.876 & 6.101 & 6.237 \\
\hline 0.8 & 5.72 & 5.300 & 5.838 & 6.915 \\
\hline 1 & 5.12 & 5.141 & 5.244 & $5.259 \pm 0.039$ \\
\hline 1.2 & 4.5 & 4.512 & 4.603 & 4.53 \\
\hline 1.4 & 3.91 & 3.932 & 4.002 & 3.898 \\
\hline 1.6 & 3.41 & 3.435 & 3.480 & 3.345 \\
\hline 1.8 & 2.99 & 3.017 & 3.039 & 2.905 \\
\hline 2 & 2.67 & 2.691 & 2.698 & $2.595 \pm 0.028$ \\
\hline 3 & 1.85 & 1.867 & 1.873 & 1.769 \\
\hline 4 & 1.46 & 1.477 & 1.475 & 1.414 \\
\hline 5 & 1.14 & 1.147 & 1.138 & $1.114 \pm 0.017$ \\
\hline 6 & 0.867 & 0.875 & 0.867 & 0.862 \\
\hline 7 & 0.665 & 0.672 & 0.665 & 0.647 \\
\hline
\end{tabular}

Table 2: Gives various theoretical $\mathrm{J}\left(\mathrm{P}_{\mathrm{Z}}\right)$ values by applying the superposition model for (MoTe $)_{2}$ with the experimental values (Mohammad, F.M., 1989).

\begin{tabular}{|c|c|c|c|c|}
\hline \multirow[b]{3}{*}{$\begin{array}{l}P_{Z} \\
\text { (a.u.) }\end{array}$} & \multicolumn{4}{|c|}{$\mathrm{J}\left(\mathrm{P}_{\mathrm{Z}}\right)$} \\
\hline & \multicolumn{3}{|c|}{ Superposition model } & \multirow[b]{2}{*}{ Exp. [16] } \\
\hline & Free atom & Free electron & $\begin{array}{ll}\mathrm{MoTe}_{2} & \mathrm{RFA}\end{array}$ & \\
\hline 0 & 27.68 & 24.942 & 24.530 & $24.552 \pm 0.043$ \\
\hline 0.1 & 27.28 & 24.848 & 24.436 & 24.47 \\
\hline 0.2 & 26.28 & 24.507 & 24.103 & 24.195 \\
\hline 0.3 & 24.91 & 23.839 & 23.464 & 23.718 \\
\hline 0.4 & 23.38 & 22.929 & 22.576 & 23.05 \\
\hline 0.5 & 21.08 & 21.856 & 21.426 & 22.196 \\
\hline 0.6 & 20.28 & 20.665 & 20.724 & 21.173 \\
\hline 0.7 & 18.86 & 19.598 & 19.500 & 20.066 \\
\hline 0.8 & 17.62 & 18.405 & 18.362 & 18.931 \\
\hline 1 & 15.62 & 16.420 & 16.445 & $16.711 \pm 0.033$ \\
\hline 1.2 & 14.14 & 14.351 & 14.391 & 14.929 \\
\hline 1.4 & 13.55 & 13.101 & 13.141 & 13.35 \\
\hline
\end{tabular}


Citation: Fareed M. Mohammed et al., Electronic Properties and Charge Density Transfer of $\mathrm{MoTe}_{2}$. Australian Journal of Basic and Applied Sciences, 12(7): 5055.

\begin{tabular}{|c|c|c|c|c|}
\hline 1.6 & 11.91 & 11.994 & 12.025 & 12.056 \\
\hline 1.8 & 10.93 & 10.977 & 10.999 & 10.936 \\
\hline 2 & 10.003 & 10.063 & 10.076 & $9.955 \pm 0.022$ \\
\hline 3 & 6.59 & 6.614 & 6.612 & $6.495 \pm 0.016$ \\
\hline 4 & 4.72 & 4.729 & 4.729 & $4.730 \pm 0.012$ \\
\hline 5 & 3.68 & 3.666 & 3.666 & $3.638 \pm 0.010$ \\
\hline 6 & 2.947 & 2.944 & 2.944 & $2.892 \pm 0.008$ \\
\hline
\end{tabular}

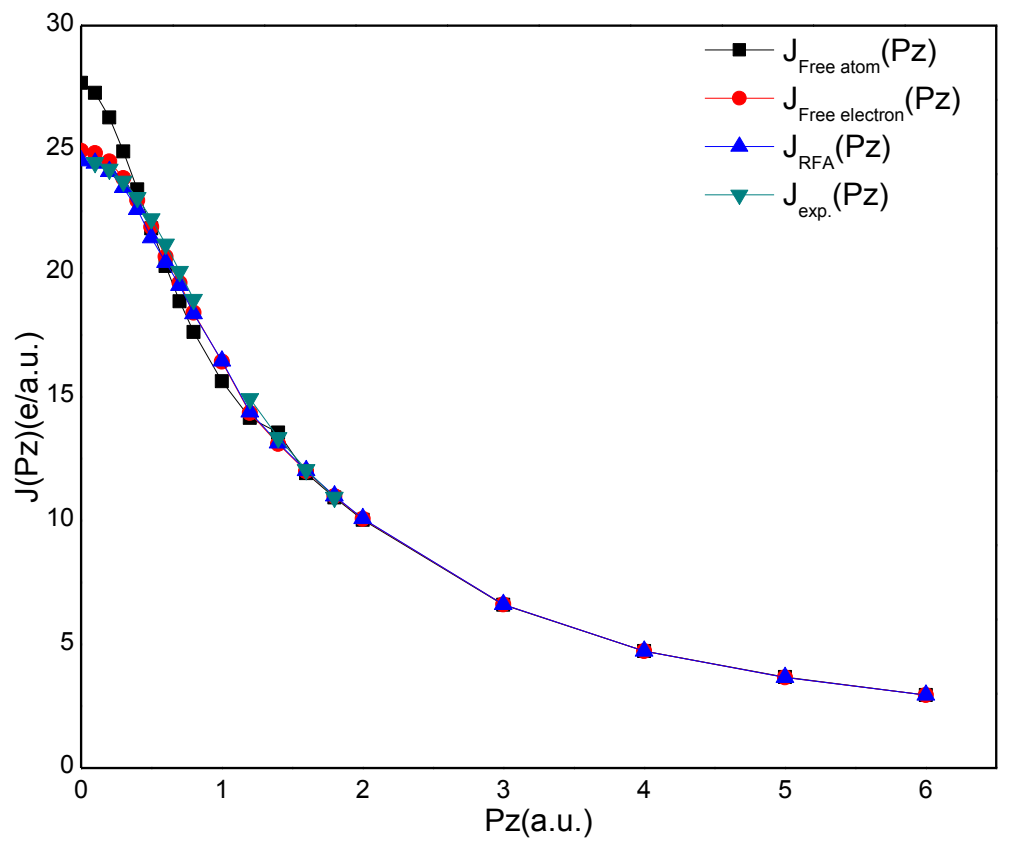

Fig. 3: Comparison of the theoretical results for Compton profiles with the experimental (Heda, N.L., 2010) for MoTe 2 .

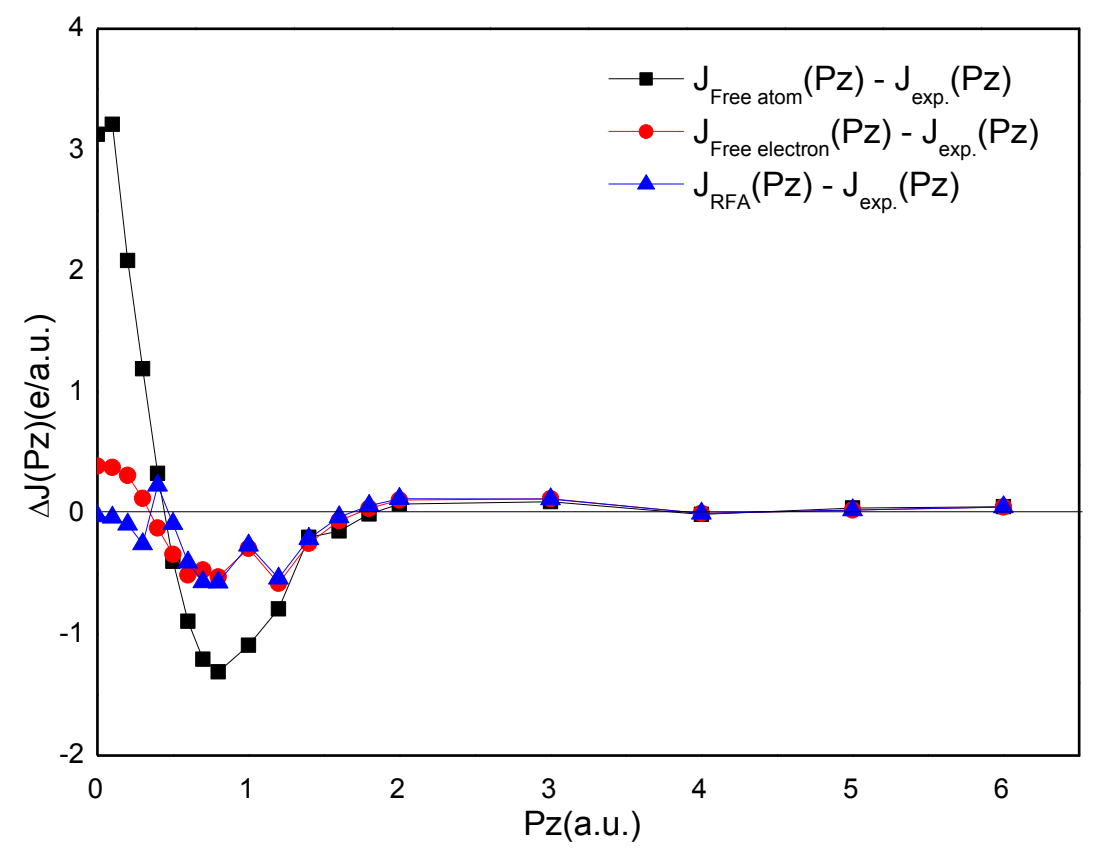

Fig. 4: Difference between the theoretical Compton profiles and the experimental (Heda, N.L., 2010) of MoTe ${ }_{2}$.

In this work we have reported the charge transfer in $\mathrm{MoTe}_{2}$ compound by applying the simple ionic model the amount of charge transfer is 1.4 electrons from Te atom to Mo atom which reveal that bonding in $\mathrm{MoTe}_{2}$ is ionic (or less covalent). Which is agree with experimental data. 


\section{REFERENCES}

Ahuja, B.L., B.K. Sharma and O. Aikala, 1987. Pramana J. of Physics, 29: 313.

Berggren, K.F., 1972. Phys. Rev. B6: 2156-61.

Berggren, K.F., S. Manninen and T. Paakkari, 1973. Phys. Rev., B552516.

Bigges, L., L. Mendelsohn, J.B. Mann, 1975. At. Data Nucl. Data Tables, 16: 201.

Cooper, M.J., 1985. Rep. Prog. Phys., 48: 415.

Clementi, E. and C. Roetti, 1974. 14: 177.

Dawson, W.G., D.W. Bullett, 1987. J. Phys. C: Solid State Phys., 20: 6159.

Heda, N.L., 2010. ALPa Dashora, Ambica Marwal, Yamini Sharma,S.K. Srivastava Gulzar Ahmed, Rajesh Jain, B.L. Ahuja "J. Phys. Chem. of solids" 71: 187-193.

Hind, S.P., P.M. Lee, 1980. J. Phys. C: Solid State Phys., 13: 349.

Kam, K.K., B. Parkinson, 1982. J. Phys. Chem., 86: 463.

Mohammad, F.M., B.K. Sharma, H. Singh and B.L. Ahuja, 1989. Phys. Stat. Sol. (b) 152: 145.

McGovern, I.T., R.H. Williams, A.W. Parke, 1979. J. Phys. C: Solid State Phys., 12: 2689.

Paakkari, T. and S. Manninen, 1974. J. Phys. F., 4: L 133.

Th. Böker, R. Severin, A. Müller, C. Janowitz, R. Manzke, D. Vob, P. Krüger, A. Mazur, J. Pollmann, 2001. Phys. Rev., B 64: 235305.

Timms, D.N. and M.J. Cooper, 1993. 48a: 343.

Williams, B.G., 1977. (Mc Graw-Hill, London), pp: 11.

\section{ACKNOWLEDGMENT}

The authors would like to thank the dean of college of science and the president of the University of Tikrit for their supports and the department of Physics for putting all the facilities under this our disposal without this work will not be a cheived. 